\title{
Constipation Is Also an Important Cause of Fecal Incontinence in Old People
}

TO THE EDITOR: I read the report by Kang et al ${ }^{1}$ regarding "prevalence and predictive factors of fecal incontinence." In this study, most of fecal incontinence was mild form and related with water or loose stool consistency. The result was consistent with report by Bharucha et al. ${ }^{2}$ I believe that bowel disturbance (ie, diarrhea and irritable bowel syndrome) is the most common cause of fecal incontinence of community people. It is to be noted that most of fecal incontinence was mild form in these studies. The patients with fecal incontinence are often embarrassed to discuss the symptoms. Therefore, I wonder whether health care use is of importance among patients with fecal incontinence in association with diarrhea or irritable bowel syndrome. Kang et $\mathrm{al}^{1}$ reported that functional constipation was one of the significant predictive factors for fecal incontinence in subjects above 50 years old. From my own experience, constipation (or fecal impaction) is the most common factor that drives medical care seeking among patients with fecal incontinence. Fecal incontinence associated with constipation is likely to be commonly encountered in older hospitalized patients. Most of them need to change the underwear because of fecal material. Inability to sense and respond to the presence of stool in the rectum is often seen among these patients. Constipation, especially excessive straining during evacuation, may contribute to pelvic floor weakness. ${ }^{3}$ Ultimately, excessive descent causes a stretch-induced pudendal neuropathy, and makes the anorectal angle obtuse, impairing the flap valve that normally maintains continence when intra-abdominal pressure increases. Constipation may be a cause of rectal hyposensitivity, which appears to play a significant role in the pathogenesis of fecal incontinence, especially in patients with fecal impaction or megarectum. ${ }^{4}$ I believe that as the proportion of older people in South Korea is increasing, constipation may become a more important issue related with socioeconomic burden in patients with fecal incontinence.

Tae Hee Lee

Institute for Digestive Research, Soonchunhyang University, College of Medicine, Seoul, Korea

1. Kang HW, Jung HK, Kwon KJ, et al. Prevalence and predictive factors of fecal incontinence. J Neurogastroenterol Motil 2012;18:8693.

2. Bharucha AE, Zinsmeister AR, Schleck CD, Melton LJ 3rd. Bowel disturbances are the most important risk factors for late onset fecal incontinence: a population-based case-control study in women. Gastroenterology 2010;139:1559-1566.

3. Harewood GC, Coulie B, Camilleri M, Rath-Harvey D, Pemberton $\mathrm{JH}$. Descending perineum syndrome: audit of clinical and laboratory features and outcome of pelvic floor retraining. Am J Gastroenterol 1999;94:126-130.

4. Gladman MA, Lunniss PJ, Scott SM, Swash M. Rectal hyposensitivity. Am J Gastroenterol 2006;101:1140-1151.

Conflicts of interest: None. 